\title{
UNA PINTURA DE LA "ILUSTRACIÓN" MEXICANA
}

\author{
P O R
}

\section{FRANCISCO DE LA MAZA}

Cuando se escribe sobre la "Ilustración" mexicana se recurre a los jesuitas desterrados: Clavijero, Alegre, Abad, Márquez, Campoy; se recuerda al científico Antonio Alzate y sus Gacetas; se evoca al doctor Ignacio Bartolache y su Mercurio Volante; son exhumados el bótanico José Moziño, el químico Fausto de Elhuyar y el médico José Luis Montaña; se habla de El Despertador Americano de Francisco Maldonado y de las andanzas de Servando Teresa de Mier; se transcriben los peores párrafos de Fernández de Lizardi y se cae de rodillas ante Humboldt.

Todo eso está bien, pero se olvida la labor "ilustrada" en el campo del Arte. Se olvida que el estilo neoclásico, destructor del religioso barroco, es "ilustrado" y que tanto contribuyeron al movimiento intelectual e histórico de la "Ilustración" arquitectos como Costanzó, Tolsá, Castera, González Velázquez y Tresguerras, como los científicos y literatos. $Y$ científico fue también Costanzó y literato fue también Tresguerras. Manuel Tolsá, proyectando un cementerio modelo de carácter civil, el primero de América, es un "ilustrado", y Tresguerras, ese Ponz americano puesto en práctica de aluvión, lo es aún más. ${ }^{1}$

1 Véanse "Algunas obras desconocidas de Manuel Tolsá", en Anales del Instituto de Investigaciones Estéticas, No 14 y Ocios Literarios de Francisco Eduardo Tresguerras de la Serie de Estudios y Fuentes del Arte en México, No xil, del nismo Instituto. 
En el campo de la pintura fue donde menos -donde casi nadahizo la "Ilustración". El arte pictórico siguió siendo devoto, cortesano y tradicionalista. Apenas si José Luis Rodríguez Alconedo levanta una cortinilla y cla el toque goyesco en sus retratos y en todo el siglo xvir! sólo hay unos cuantos cuadros no religiosos, de los cuales recordamos ahora uno: el Almacén, de Miguel Jerónimo Zendejas, de 1797, motivo de esta nota.

"Pocos pintores han sido objeto de tantas discusiones como Miguel Jcrónimo Zendejas - dice Manuel Toussaint-, mientras unos lo ponen sobre las nubes, otros le denigran de lo lindo". 2 Vayamos de estas nubes a la denigración al través de lo que se ha escrito y estudiado sobre el famoso pintor poblano.

La primera nota que se publicó sobre Zendejas fue redactada por el bencmérito e infatigable novelista y periodista Manuel Payno en la hermosa edición de Ignacio Cumplido de El Album Mexicano de 1849.

Afirma Payno, creemos que por primera vez, la existencia de una "escucla mexicana" de pintura en la Colonia. Vale la pena reproducir el parrafito: "Una multitud de gentes no se acaban de persuadir todavia de que hubo en México un periodo tan feliz para la pintura, que se formó lo que puede llamarse una Escuela Mexicana, enteramente distinta de las escuelas europeas y que será mala o buena, pero que individualmente tiene su estilo, su colorido, su manera, sus cualidades, en fin, que le son propias y exclusivas y que se semejan, por ejemplo, a la escuela sevillana o madrileña, pero no se igualan absolutamente a ninguna". 3

Búrlase, sin embargo, de la pintura novohispana en general, a pesar de que al final deslice algún adjetivo elogioso: "Esos grandes lienzos de protecciones de la Virgen a alguna orden religiosa, extendiendo su manto amplísimo sobre los miembros de la comunidad, en los que aparecían retratos, desde el rollizo prior hasta los legos, que apenas alcanzaban una puntita del manto... los artistas corrian de convento en convento llenando los altares, los claustros, las sacristías, de muchos cuadros de todas dimensiones y muchos de ellos maravillosos..."

Volviendo a Zendejas, nos dice Payno que sus claroscuros eran

2. Arte Colonial de México. Primera edición, 1948, p. 354. Segunda edición, 1962, p. 176.

3 Una negación radical a estos conceptos, escrita por Ignacio Altamirano, puede leerse en Primer Almanaque Histórico Artístico Monumental de la República Mexicana, publicado por Manuel Caballero. México, 1883-1884, pp. 90-93. 
"magníficos" y su colorido "suave, delicado, sin amaneramientos". $\mathbf{Y}$ añade. "En todas sus cabezas hay tanta delicadeza, dulzura y expresión, que raya en defecto, pues algunas de sus figuras de réprobos y demonios participan, acaso indebidamente, de esas cualidades". Le censura que, en lo que andaba atrasado, era "en la perspectiva y en el desnudo".

Como persona era Miguel Jerónimo "generoso, amable, altamente moral y complaciente"; una vez le pintó a una viejecita una Virgen de los Dolores por veinte reales, pintura que acabó, dignificada, en la pinacoteca del "ilustrado" obispo Joaquin Pérez Martínez.

Después de Payno hay un "estudio", por así decir, sobre Zendejas, de un señor Jorge Hammeken y Mexía, que no es sino una feroz y superficial diatriba contra la Epoca Colonial y una pueril exaltación del pintor "que es el artista más notable que ha producido México desde la conquista hasta nuestros dias". 4

Por ser chisme chistoso transcribimos la siguiente leyenda del pobre señor Hammeken: "Zendejas jamás comenzaba sus cuadros trazando boceto, diseño o dibujo alguno; ideada una vez la composición en la riquísima tela de su fantasía, preparábase a darle forma siguiendo un sistema sencillísimo: escogía su tela -generalmente de tres o cuatro varas de largo- y la fijaba sobre una varilla delgada de madera, cuya varilla clavaba en la pared a la altura de su cabeza; después desenvolvía una vara de este lienzo y comenzaba la composición dando principio a sus figuras por la parte superior; una vez llenado este espacio lo enredaba de nuevo en la varilla y saltaba otra vara de lienzo virgen y así sucesivamente hasta completar el cuadro". No vale la pena comentar semejante paparrucha cuando el psitacismo se apodera en esta forma de un cerebro humano.

Elogia y describe después un Calvario sin molestarse en decirnos dónde estaba; lo compara con otro cuadro del mismo tema del Guercino y acaba: "Lo que distingue a Zendejas de los otros pintores mexicanos es una gran originalidad en la composición; era audaz hasta la temeridad; su clibujo es incorrecto, pero tiene la incorrección que proviene de la ignorancia, y no del amaneramiento; su colorido es suave y duIce, como tiene que ser suave y dulce el colorido de un artista cuya patria es México".

El cauteloso don Manuel G. Revilla sólo nos dice que "pintaba con un no sé qué de atractivo que explica por qué fuesen bastante estima-

4 En Hombres ilustres mexicanos, de Eduardo L. Gallo. Editor, México, 1874, Tomo 1II, pp. 35 a 57. 
das sus obras", y añade: "con todo, abundan las malas que llevan su firma, y es que algunos pintores de inferior mérito la solicitaban para prestigiar sus trabajos sin que de ello hiciera él escrúpulo". 5 Esta leyenda -o verdad- la contaron después sus discípulos, tal vez generalizando lo que hizo en una o dos ocasiones en un rato de generoso buen humor.

Por último, los historiadores que mejor se han ocupado de Zendejas (como de la pintura novohispana en general) son don Francisco Pérez Salazar y don Manuel Toussaint. El primero en su utilísimo estudio Algunos datos sobre la pintura en Puebla en la época colonial, en "Memorias y Revista de la Sociedad Científica Antonio Alzate", 1923, tomo xLI y el segundo en su Historia de la Pintura Colonial, aún inédita. ${ }^{6}$

Nació Miguel Jerónimo Zendejas en Puebla el año de 1724. Su padre fue comerciante y estuvo una vez en Europa, llevado por el jesuita Oviedo. De Italia se le ocurrió traer -y luego encargar- grabados, artístico material que agregó a su tienda y que mucho debió servir a los pintores de su tiempo.

Miguel Jerónimo fue aprendiz de Pablo Talavera y luego oficial de Joaquín Magón y de Gregorio Lara Priego. Como fue casado con Brigida Priego, se supone que ésta fue hija de aquél. En su trabajo como aprendiz de Magón le ayudó en la rica decoración del coro alto de Santa Rosa (c. 1760), de lo cual José Manzo, su discípulo, inventó la siguiente leyenda: "Cuando el obispo don Pantaleón Alvarez de Abreu (1743-1763) repuso el coro de Santa Rosa, iba diariamente a casa del artista en su carroza y lo acompañaba una gran parte del día en sus trabajos". ${ }^{7}$

La exageración es atroz candar un obispo diariamente y aun gran parte del dia a la zaga de un pintor desconocido? Demasiado quehacer tendría para hacer esas visitas y con esa frecuencia y puntualidad que pasan de gentileza. Ni para hacerlas con Magón estarían justificadas, menos aun para su aprendiz. Habría que estudiar con detenimiento

- El Arte en México, 1923, segunda edición, p. 152.

- En prensa la segunda edición, con el título de Historia de la Pintura Colonial en Puebla, y un estudio de Elisa Vargas Lugo, edición del Instituto de Investigaciones Estéticas. Asimismo se prepara la publicación del citado libro de Manuel Toussaint.

7 Citado por Manuel Payno. 
este coro extraordinario para distinguir lo que es de Magón y lo que es de Zendejas.

Lo que sí sabemos es que cuando el prelado murió, en 1763, para hacer la pira funeraria de su corazón, en la misma iglesia de las Rosas, "se eligió a uno de los más diestros pintores de esta ciudad, que lo fue don Jerónimo de Zendejas, examinado en el Arte", como pudo leer muy satisfecho el propio artista en el libro: El Corazón de las Rosas sepultado entre fragancia... publicado en 1764 por el doctor José Isidro Montaña. 8

Antes de 1760 se conoce un retrato, fechado en 1758, de Ignacio Gómez Altamirano que, según Toussaint, existe en la Untiversidad de Puebla. Se supone de ese año otro retrato de la misma Universidad, en el Salón General, de Juan Fernández de Villanueva.

En 1764 pintó los óleos del camarín de la Capilla de los Dolores en la parroquia de Acatzingo y en 1774 firma - "Migl. Geron. Sendejas"el gran San Bernardo ante Cristo del sotocoro de San Juan de Dios, en Puebla.

De 1775 a 1778 son los lienzos de la nave de la citada capilla de Acatzingo, que son: La calle de la Amargura; Los apóstoles dándole el pésame a la Virgen; El Descendimiento; La Piedad y La Crucifixión. En 1776 firma una Coronación, en el Museo de Santa Mónica.

De 1777 es la Virgen Peregrina, del mismo lugar y dos cuadros pequeños, y muy buenos, de la vida de San Agustín: Muerte del santo y San Agustin alimentado de sangre de Cristo y leche de la Virgen, hoy en el Museo de Santa Mónica. En este mismo, dos lienzos de igual tamaño que los anteriores, con escenas de Via-crucis, fechados en 1778.

Para la magna iglesia de San José de Puebla pintó un retablo, el primero de la nave izquierda, en 1780, con cinco óleos: el central es la Muerte de San José ${ }^{\ominus}$ y los cuatro laterales El florecer de la vara; Presentación al templo antes de los desposorios; Glorificación del santo y el Taller de carpinteria.

De la colección Franz Mayer es un Cristo de 1781 y de ese mismo año la importante serie de la Vida de San Ignacio de Loyola, de la cual existen seis en la Capilla de Jesús Nazareno del templo de San José, en Puebla. En 1783 fecha la Virgen de la Luz, de Tehuacán.

8 Véase F. de la Maza, Las Piras Funerarias en la Historia y en el Arte de México, Ed. Instituto de Investigaciones Estéticas, México, 1946, pp. 101-104.

- Reproducción en Pinturas Poblanas, de José Luis Bello y Gustavo Ariza, Mć. xico. Ed. Atlante, 1943, lám. xvirr. 
El año de 1784 fue fecundo para Zendejas y de enriquecimiento decorativo para el citado templo de San José. En el coro de la Capilla de Jesús Nazareno hay un mural con cinco escenas: La Última Cena; San Pedro comulga a la Virgen; un Niño que lleva viandas a la Cena, trozo del mural que aprovechó el pintor para darnos un imponente "cuadro de género" con piezas de plata, cobre y cerámica; Melquisedec y David. Haciendo simetría con éste, pero en la parte exterior, sobre el arco de la entrada, otro mural con Jesus Nazareno en el medio punto; y Repartición de los panes; Magdalena; Samaritana y Expulsión de los mercaderes del templo. En el crucero opuesto: Coronación de San José (con tres figuras de suma importancia para este estudio, pues quince años antes del Almacén ya Zendejas habia pintado parecidas damas simbólicas, si bien aquí son Europa, Asia, América - África fue cortada para adaptarla al sitio mencionado lo que quiere decir que estos lienzos no fueron hechos para el Templo de San José-, tan ricas, enjoyadas y hasta parecidas físicamente como las que haria en 1797); Santa Ana; San Joaquin; la Visitación y la Anunciación.

Los dos interesantes cuadros de La Confesión de la Reina con San Juan Nepomuceno, El intento de cohecho del Rey y el Tormento y muerte de San Juan Nepomuceno, del templo de la Concordia, capilla izquierda del sotocoro, son de 1792 y de ese mismo año tal vez - no he podido comprobarlo- los seis poderosos lienzos de la Vida de San Felipe Neri, de la nave de la misma iglesia.

En la Catedral poblana, en el altar del Perdón, están unos cuidadosos San Miguel y Angel de la Guarda y los cuadros de ánimas de las predelas, obras de 1797. Tal vez por esas fechas pintó lo mejor de su obra: nos referimos a la decoración que hizo del Coliseo de Puebla -hoy el restaurado Teatro Principal- y que se había estrenado desde 1760. Los murales fueron: en la bóveda, los retratos de Tirso de Molina, Calderón de la Barca, Juan Ruiz de Alarcón y Agustin Moreto, además del de I'ernando VI; sobre el arco del proscenio estaban las figuras de Apolo y Talia flanqueando el escudo de la ciudad de Puebla.

En 1806 fecha un Gozo de la Virgen: la aparición de Cristo resucitado, que está en el vestíbulo de la iglesia de San José, y en 1809 hizo las pin. turas para un arco triunfal y los diez murales con cuarenta y ocho escenas de la Vida y milagros del Beato Sebastián de Aparicio, en su capilla de San Francisco. Su última obra, La Oración del Huerto, es de 1815, pintada, según graciosa expresión de Olivares Iriarte "al borde 
de la cama" en su lecho de muerte y que está en el altar mayor del Sagrario de Puebla.

Recordemos, en fin, que retrató a dos monjas de Santa Rosa, una de ellas la escritora ascética Sor María Ana Agueda de San Ignacio, pinturas que existen en la sacristía de dicha iglesia, y que hizo los hermosos dibujos que grabaria Nava de las vistas de la Biblioteca Palafoxiana.

En el Museo de San Ángel, D. F., hay un curioso cuadro alegórico con San Ignacio de Loyola, la Trinidad y una Doncella, retocado, que indudablemente es de Zendejas.

Por último, Manuel Toussaint añade otro cuadro que no conocemos. Dice: "Tengo noticia de una pintura popular que, además de curiosa, es interesante porque nos revela al patriota que expresa, de modo plástico, el ambiente de independencia que ya comenzaba a reinar por todas partes. La tela representaba a una india ataviada con rica camisa y dando de mamar a tres españolitos (sic) en tanto que dos niños indigenas están llorando. La coloración era fresca. El cuadro tenía una leyenda que así rezaba:

\section{Nunca se ha visto \\ lo que aquí estamos palpando: \\ los hijos propios gimiendo \\ y los ajenos mamando}

y que procede, al parecer, del Negrito Poeta, con variantes." 10

De fines del siglo xvin debe ser su autorretrato (Col. Montes de Oca), que lo representa de frente, con su mirada de zorro al soslayo, muy blanco, y de firmes facciones. Lleva paleta y pinceles y un crucifijo enorme detrás. Fue esta pintura retocada a fines del sigla xix por un tal Toquero, que le añadió el crucifijo, pues no aparece en el dibujo que de ese autorretrato hizo su discípulo Julián Ordóñez hacia 1840 y del cual se sacó la litografía que el citado Payno publica en El Album Mexicano. ${ }^{11}$

Cuando murió fue enterrado en Santa Rosa.

10 Historia de la Pintura Colonial (ms. inédito). Hay que hacer notar que este tema fue general, por así decirlo, en Hispanoamérica, pues hay otra pintura con el mismo tema, anónima, en Montevideo, con una leyenda parecida: "Dónde se ha visto cn el mundo lo que aquí estamos mirando... / Ios hijos propios gimiendo y los extraños mamando" (publicado en Art and Architecture in Spain and Portugal and their American dominions, por Gcorge Kubler y Martin Soria, 1959, p. 327, ilus. tración $179 \mathrm{B.}$.).

11 Pinturas Poblanas, de José Luis Bello y Gustavo Ariza, México. Ed. Atlante, 1943, p. 122. 
El Almacén es un conjunto de varias tablas que servian de puertas a una enorme alacena o almacén, como está bien llamado, para guardar los tarros de especias, minerales en polvo, sales y toda clase de medicamentos. Perteneció a la botica de Ignacio Rodríguez Alconedo (fig. 1).

Estuvo esta botica en la casa $\mathrm{N}$ 8 de la calle de Los Miradores, hoy avenida Reforma N` 500 y existió hasta 1922 . La pintura del almacén pertenece ahora al Museo de Chapultepec, donde está colocada, indebidamente, en forma de biombo. Hugo Leicht piensa que los tableros "servian de puertas para los estantes en el ángulo de dos paredes contiguas. Son de 9 metros de largo y 3 de alto". Añade que don Manuel Mariano Fernández pudo ser miembro de la familia del historiador don Mariano Fernández de Echeverría y Veytia. ${ }^{12}$

Eran las boticas coloniales un trasunto de las españolas, como es natural, y conservaban ese ambiente de tugurio alquimista que venía desde la: Edad Media. No andaban muy lejos de la de Romeo y Julieta: "Del techo de su sórdida tienda colgaban una tortuga, un caimán disecado y otras pieles de peces disformes; sobre sus estantes distinguiase un pobre surtido de cajas vacías, tarros verditerrosos, vejigas y mohosas simientes, retazos de bramante y viejos panes de rosas, todo ello en orden desigual, para que hiciera más ostentación." 13

Y Aldous Huxley recuerda otra descripción de farmacia del siglo xvi del Dispensary de Garth: "Aquí momias muy dignamente viejas y allí la tortuga colgaba su cota de malla y las drogas en mohoso amontonamiento se pudrian; alli secas vejigas y dientes arrancados yacían ..." 14

Mas sin ir tan lejos, en la Gaceta de México tuvo a bien publicar Alzate una traducción de A. G. Camus, un famoso naturalista francés (1740-1804), en la que se burla de una farmacia del siglo xviı: "Si nos encaminamos para registrar las oficinas de botica, observaremos una larga serie de medicamentos o, por hablar con verdad, un embrollo de simples, cuyos nombres retumbantes confunden a la imaginación y a la memoria... acerquémonos para registrar las gavetas y botes que con tanta profusión adornan los farmacéuticos: en un hermoso vidrio registraremos el excreto de perro, descifrado con los nombres muy subli-

12 Las Calles de Puebla, Puebla, 1934, pp. 250-251.

13 Acto V, Escena I.

14 En Los Demonios de Loudun, Ed. Hermes, 1953, p. 50. 
mes de album grecum y de cinocropus; en otro las cagarrutas de ratón con la expresión nigrum grecum; veremos otra botella que por distintivo tiene el rotulón enfático de mil flores y su contenido no es otra cosa que orines de vaca ... me extremezco si dirijo la vista hacia ciertos armarios, porque veo los cráneos de hombres muertos súbitamente y los huesos de los ahorcados con que se preparan ciertos polvos que nombran especificos; observo las momias, cuya antigiiedad y virtudes se preconizan... (Pero ahora) ha sido preciso enderezar los genios extraviados hacia la naturaleza, que desconocian porque la habían desfigurado... la medicina camina en el día por sendas menos escabrosas y más seguras y anhela por la reforma de los abusos que se han introducido en la farmacia o arte que prepara los medicamentos ... esta reforma que propongo de la farmacia parecería ideal si no me extendiese detallando lo principal... son necesarios para su manipulación genios adornados de muchas luces y grandes conocimientos ... la farmacia es el arte de distinguir, escoger y preparar las medicinas ..." 15

¿Y cómo no iban a ser así las boticas si aun el primer "museo" de la Academia de Bellas Artes (l) de Puebla tenía tal batiborrillo de objetos absurdos que causa, no sé si conmiseración o espanto, leer el párrafo que le consagra Antonio Carrión en su Historia de Puebla. Tenía aquel engendro: "Una momia de mujer y otra de niña dentro de un nicho y encima de él está una vasija de cristal que contiene un feto en espíritu de vino... una colección de conchas, caracoles y mariscos curiosos... un estante que contiene 34 frascos con fetos humanos, culebras y reptiles... una espada del pez de este nombre... varias cornamentas de ciervos ... esqueletos de niños, cráneos ... conchas de armadillos ... pieles de lagarto..." 18

Recordemos, en fin, que "Don Pedro López de Villaseñor, vecino de esta ciudad, con botica pública en ella en la esquina de la Plaza y camino de Cholula" fue "sin duda el más interesante entre todos los cronistas de la ciudad de Puebla", según dice, con exagerado entusiasmo, el cronista de López de Villaseñor, o sea, el joven médico y culto historiador Efraín Castro Morales. 17

Por último, volviendo a Carrión, tomamos este histórico-farmacéutico

15 Gacetas de Literatura de México, por D. José Antonio Alzate Ramírez... Puebla, (reimpresión), 1831, pp. 217-220.

10 Op cit., 1896, tomo I, pp. 462-463.

17 Véase Pedro López de Villaseñor, Cartilla Vieja de Puebla. Ed. de José I. Mantecón. Introducción de Efraín Castro Jr. Imp. Universitaria, 1961. 
dato: "En el convento de Santa Clara hubo la particularidad de que existió una gran botica, hecha toda por las monjas, quienes fabricaron los armazones de madera, puertas, mesas y mostradores y, además, confeccionaban todo género de medicinas y daban muchas gratis a los pobres que iban a la portería con o sin recetas a pedirlas." ${ }^{18}$ Por supuesto que los franciscanos tenían en su convento una buẹa botica para uso de ellos desde 1696, así como, más o menos surtidas, las había en otros monasterios de la antes levítica ciudad de la Puebla de los Ángeles.

Y un buen día la botica de la calle de los Miradores quiso limpiarse y modernizarse. Cambió de muebles y de tarros; quitó esqueletos y pieles y se enriqueció con el nuevo "Almacén" en el que, según idea y dirección de José Ignacio Rodríguez Alconedo, se pintó el triunfo de las Ciencias y las Artes con las "muchas luces y grandes conocimientos" que pedía Camus.

De una manera segura y armoniosa pensó el despliegue de doncellas que irían a representarlas. A todas dio la misma categoría, así como a las alegorías que con ellas se acompañan y fue explicando al anciano Zendejas el por qué debía comenzar por la Salud y terminar con la Agricultura; el por qué sin el Discurso, la Experiencia y la Discreción, toda ciencia es vana y cómo sólo la Filosofia, en unión de la Prudencia, pueden, con todo respeto, presentar desnuda, descubrir, a la Medicina. Y todo bajo la benévola mirada de Dios.

Retrato admirable es esta gran pintura de ese movimiento del siglo xviIr, tan necesario (pese a su ansia destructiva de lo anterior) tan optimista y feliz (pese, también, a la tenaz resistencia que sufrió), que fue el padre intelectual del siglo xix y que se llamó "La Ilustración". ${ }^{19}$

Un llamativo letrero nos cuenta la historia del cuadro. Está en el cuarto tablero, a la derecha del espectador. Dice: "Se hizo este Almasen en el año de 1797 siendo Mayordomos Dn Manl Mariano Fernández y D. Anto Ruiz Cabrera y Administrador D. José Ignacio Rodríguez Alco-

18 Op. cit., tomo I, p. 254.

19 Véase el magnifico libro de Jean Sarrailh La España Ilustrada de la segunda mitad del siglo xvin, Fondo de Cultura Económica, México, 1957; la introducción de Ernesto Lemoine Villicaña a la Instrucción para aumentar las colecciones del Gabinete de Historia Natural de Madrid, en Boletin № 2 del Archivo General de la Nación, 1961 y el libro Humboldt y Mréxico, de José Miranda, Instituto de Historia, U. N. A. M. 1962. 
nedo, por cuya dirección se hizo y pintó dho Almazen". Y abajo: "Migl Geronimo Zendejas fecit". (fig. 4)

Las escenas pictóricas se suceden de derecha a izquierda, lo cual quiere decir que estaba colocado en el muro derecho de la entrada de la botica; por eso la primera escena es introductoria y dos personajes, elegantemente vestidos, invitan al cliente a pasar. Llevan casaca, calzón corto bajo la rodilla, medias blancas y zapatos negros con hebillas de plata. No usan pelucas. El primero, evidentemente, es un retrato. El caballero mira con fijeza al pintor que lo retrata, por lo cual ahora nos mira con la misma fijeza a todo espectador que se acerca al Almacén. Es un hombre robusto, de cara noble y hasta bien parecido, a pesar de la ligera papada y la incipiente calvicie. Su mirar es penetrante y vivo, a la vez que bondadoso. El segundo es de mayor edad, delgado, nervioso, de aguda narit aguileña. Para no repetir la mirada del primero, lo contempla con atención. (fig. 2) ¿Quiénes son estos señores? Es posible que sean los Mayordomos, los primeros citados en el letrero, pero eel director de la pintura, el sabio boticario y administrador, se iba a quedar sin ser retratado en el cuadro cuyas ideas había obedecido el artista? ¿No debería ser, justamente, uno de ellos, el primero, José Ignacio Rodríguez Alconedo? Mientras no se pruebe lo contrario así lo creemos. $Y$ hasta se parece, aunque lejanamente, a su hermano, el magnifico orfebre y pintor José Luis Rodríguez Alconedo.

Pasemos con ellos a la alegoría del Almacén, al mundo de las Ciencias y las Artes, que comienza a la entrada de un jardín.

La primera figura es una doncella un tanto desenfadada en su vestir pues enseña sin recato su pierna izquierda y baja el escote más de lo clebido. Va despeinada y de su oreja cuelga una gruesa perla. Es la Salud. Ahora nos explicamos por qué no tiene necesidad de arrebujarse en los amplios vestidos de la época y sí descubrir lo más posible su sano cuerpo. Da su mano derecha a un ángel que se arrodilla ante ella. Este ángel lleva el caduceo, correctamente pintado con sus alas en el vértice y las dos serpientes haciendo sus tres medios círculos a los lados. Este joven ángel, que en el fondo es Hermes o Mercurio, representa a la Medicina. ¡Y qué bello y ejemplar símbolo: la Medicina a los pies de la Salud, sirviéndola, rindiéndole homenaje! Detrás del ángel-Hermes, otra doncella levanta el velo de la salud; lleva diadema y una opulenta arracada. Es la Naturaleza que descubre a la Salud. O, como dice su letrero: Ars cum natura ad salutem conspirans, "El arte y la naturaleza se ponen de acuerdo con la salud". (fig. 3) 
Bajo este grupo otros dos personajes, de busto. Uno es un mestizo -o un indígena-, con gorro blanco en la cabeza; el otro es un criollo de vivisima expresión en su rostro que mira también fijamente al expectador con un ligero dejo de picardía. Si no hubiera unos nombres casi ilegibles en un papel junto a ellos, diríamos que eran Alconedo y Zendejas, como algunos han sugerido. Pero no, son don "Miguel de Samb..." y "S. . B Brito Cruz..." Ignoramos quiénes fueron estos señores y qué hacen aquí. Y niguno de los personajes que están en el $A l$ macén puede ser el pintor, pues ya éste tenía, en 1797, setenta y tres años y no hay allí ningún retrato de anciano de esa edad.

Sigue, dentro del jardín, una escena en la que dos jóvenes caballeros empelucados, detrás del zócalo que lleva la inscripción y firma, observan y comentan algo de dos capelos que cubren vasos con plantas. (fig. 4)

Vienen luego las figuras del Tiempo, el propio Cronos, un viejo desnudo, recostado en varios libros y ostentando una clepsidra; a su espalda la Historia, cosa lógica, con su diadema y aretes con joyas, pluma en su mano derecha y un libro abierto. Al libro sirve de atril Cronos, diciéndonos muy bien que sobre las espaldas del Tiempo se escribe la Historia. (fig. 5)

Junto va la Música, representada por dos jovencitas con sartas de perlas en los cabellos y reclinando en sus brazos dos instrumentos, la lira una de ellas y los tubos de un organillo la otra. Este grupo ya no está en el jardín, sino en un patio con arcos sostenidos por pilares. Lo divide del grupo siguiente una columna en la que va un largo letrero:

EL CAMPO, la NATURALEZA, la MÚSICA y ANATOMfA

la PINTURA con la ASTRONOMIA

[¿BOTÁNI?] CA dulce en su destreza

..... Señalan la belleza

la MEDICINA que sobrada

.... los tesoros de riqueza

.... la CHIMICA su amada

.... Ias Artes con largueza

.... dad tan elevada

.... cuidarla con franqueza

.... PINTURA delicada

[ESCUL] TURA que en esto se interesa

.... ARQUITECTURA selebrada 
DOI: http://dx.doi.org/10.22201/iie.18703062e.1963.32.748

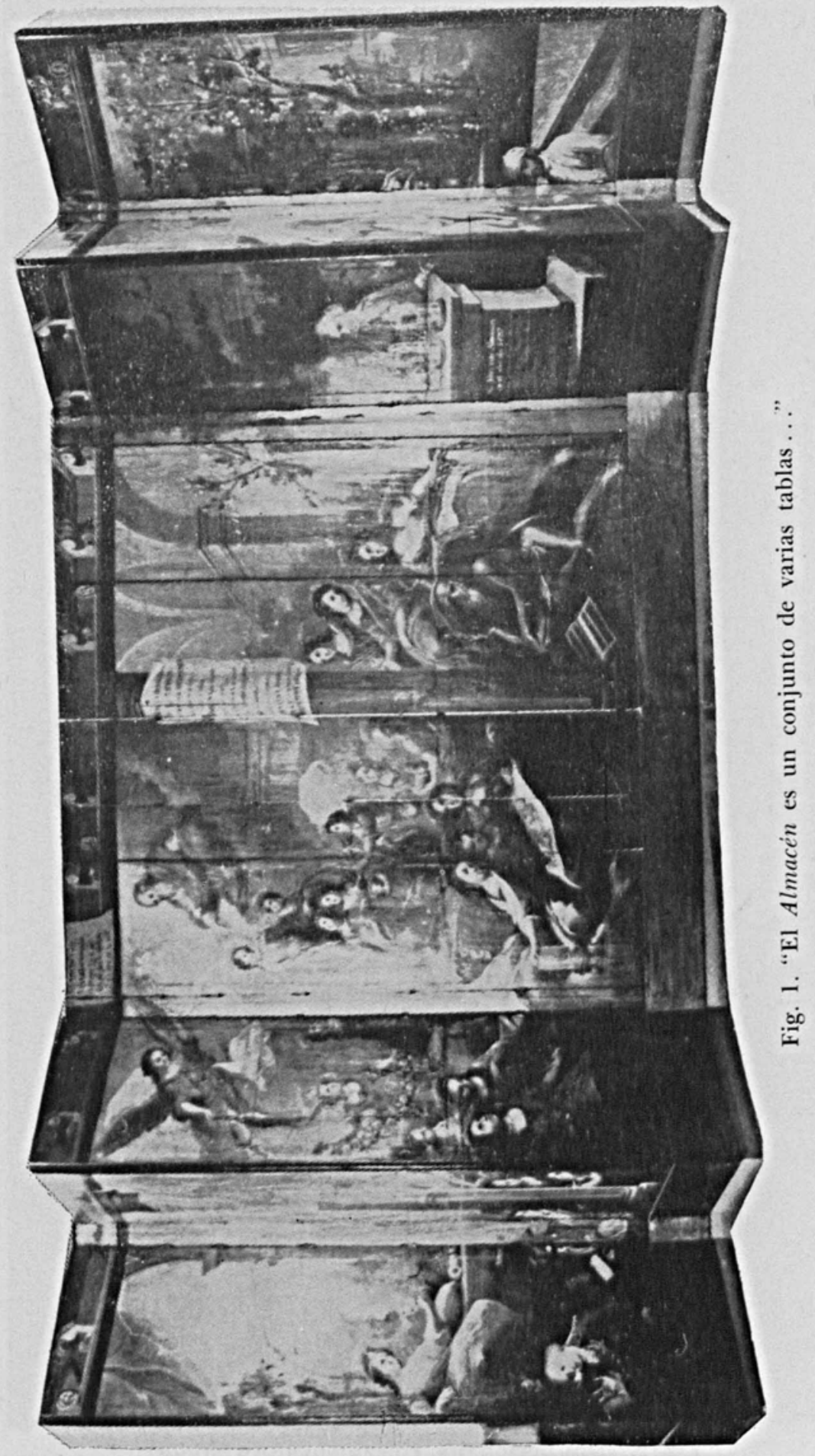


DOI: http://dx.doi.org/10.22201/iie.18703062e.1963.32.748

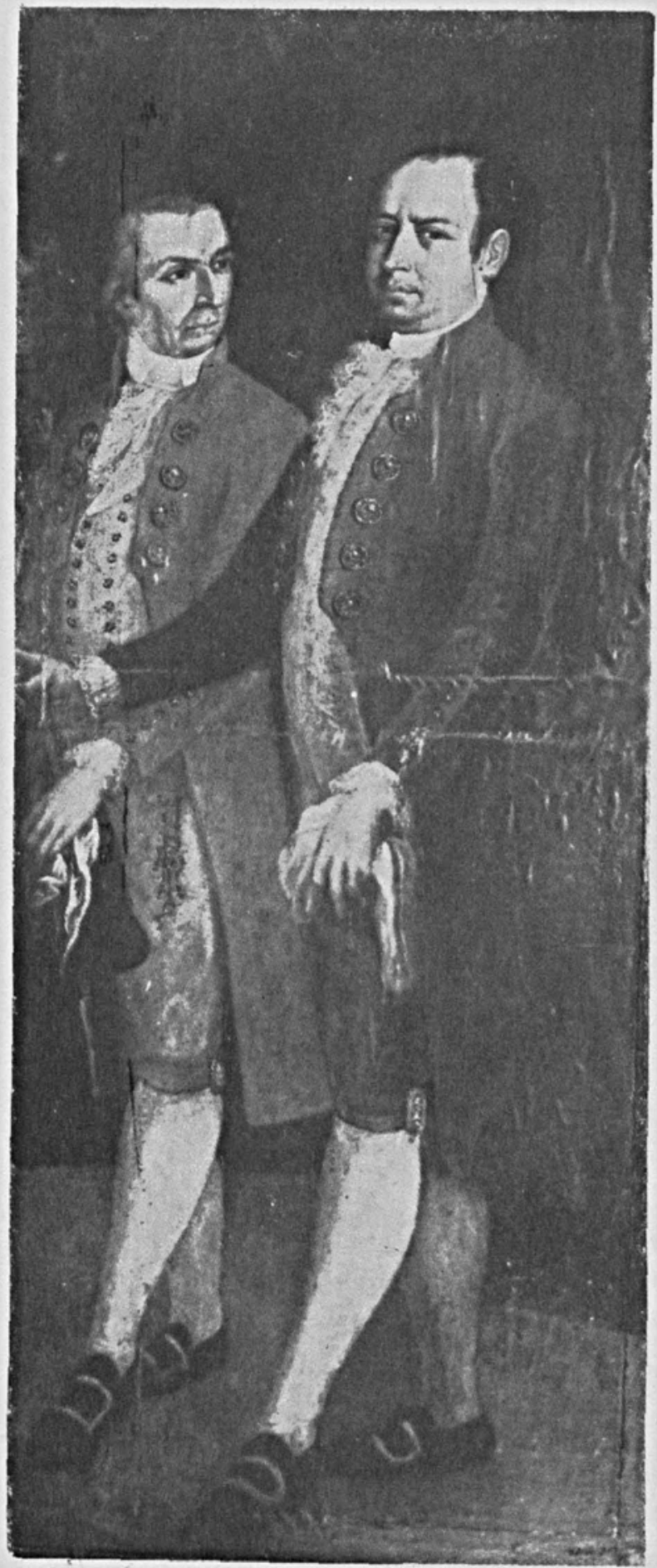

Fig. 2. "Dos personajes, elegantemente vestidos ..." 


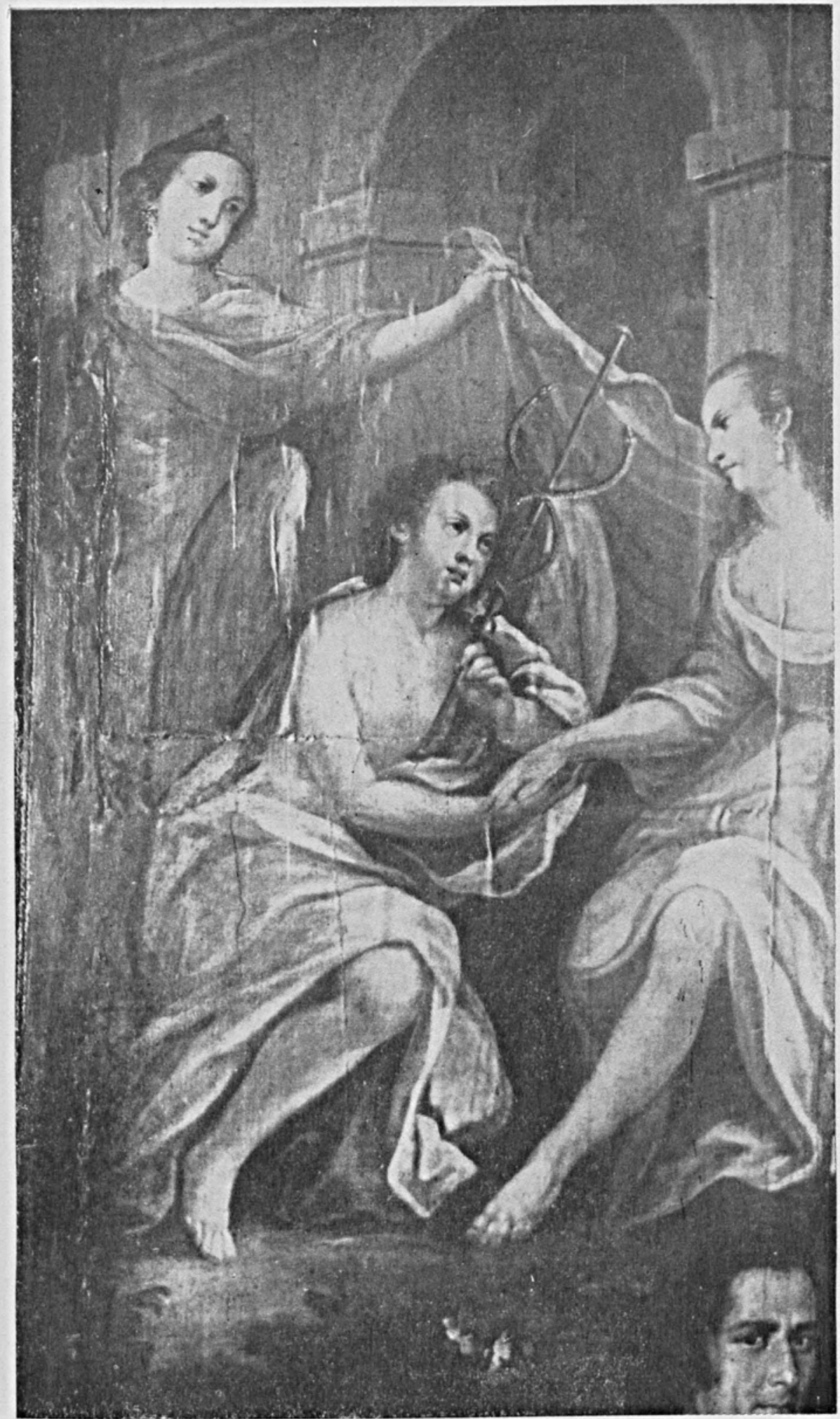

Fig. 3. Ars cum natura ad salutem conspirans... 
DOI: http://dx.doi.org/10.22201/iie.18703062e.1963.32.748

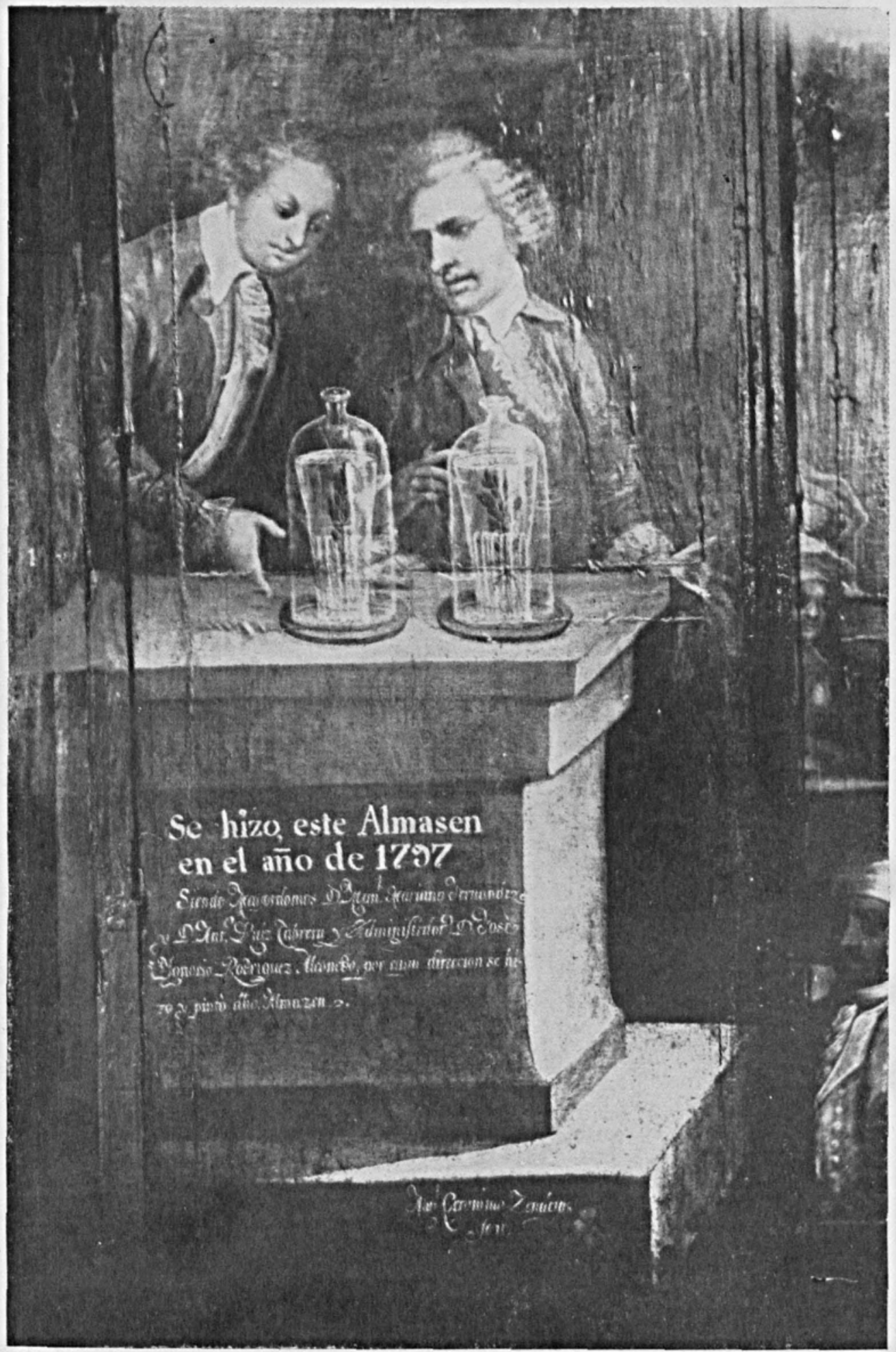

Fig. 4. "... dos jóvencs caballeros ... observan v comentan ..." 
DOI: http://dx.doi.org/10.22201/iie.18703062e.1963.32.748

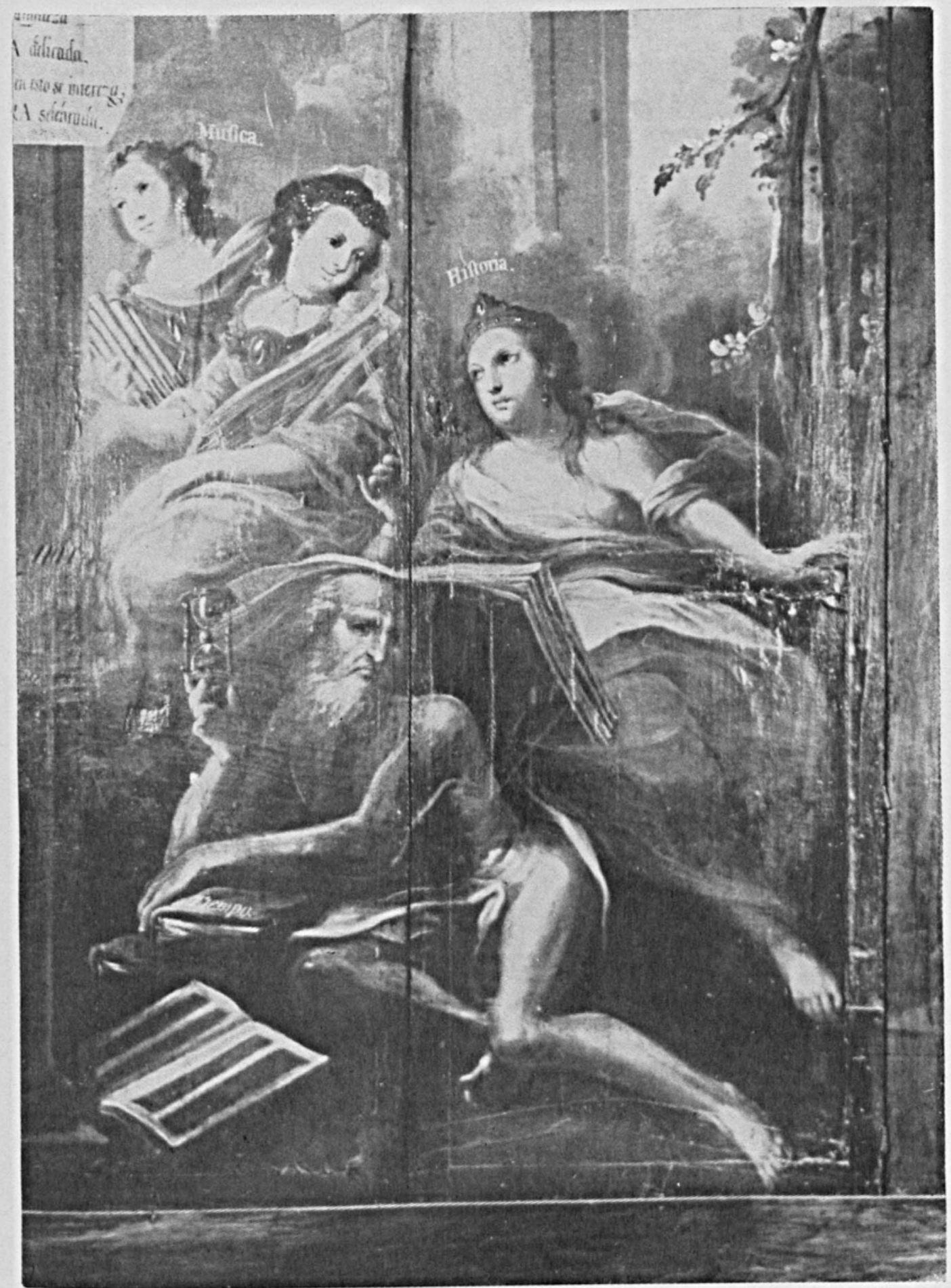

Fig. 5. "... sobre las espaldas del Tiempo se escribe la Historia..." 
DOI: http://dx.doi.org/10.22201/iie.18703062e.1963.32.748

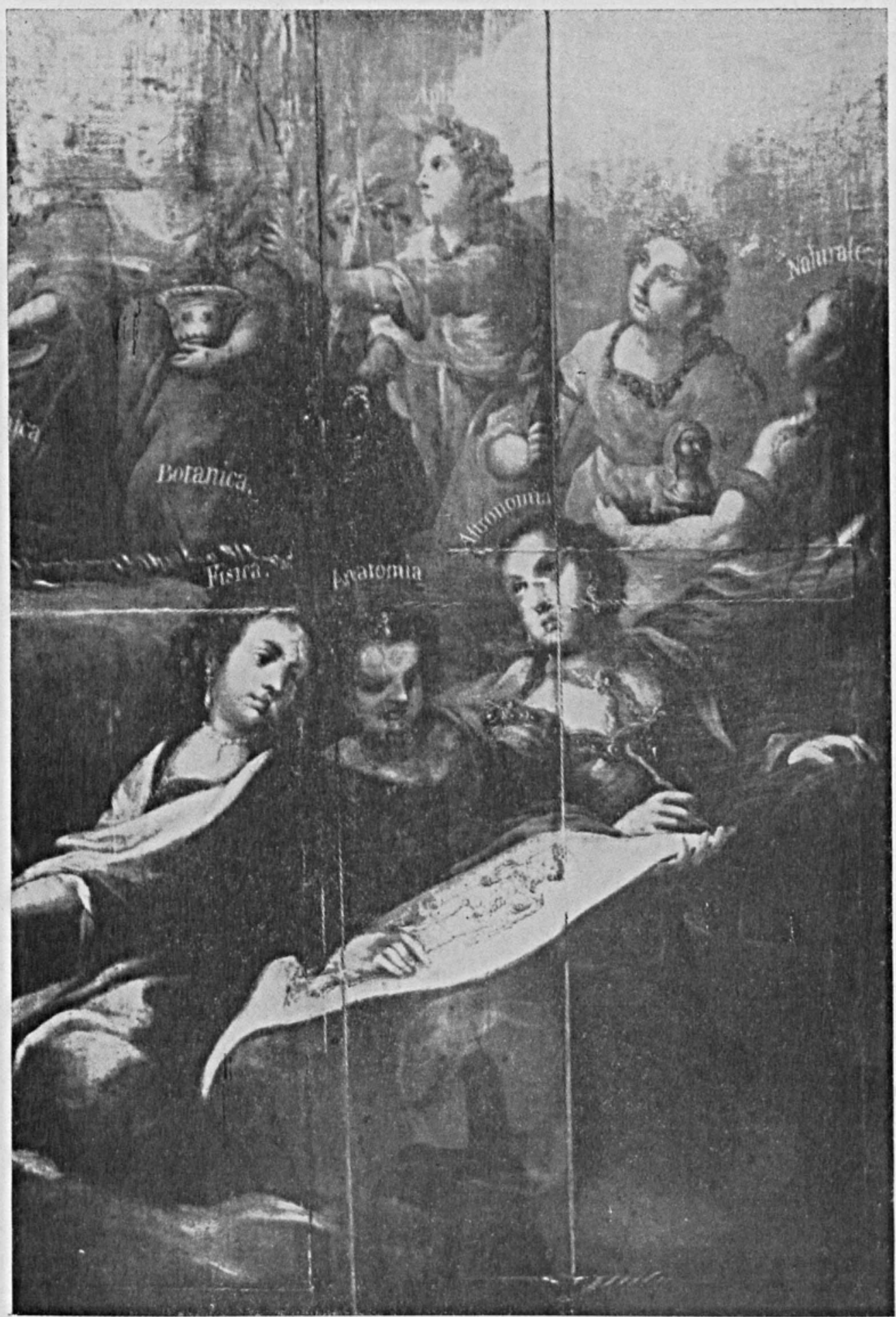

Fig. 6. Las Ciencias; en el centro la Anatomía. 
DOI: http://dx.doi.org/10.22201/iie.18703062e.1963.32.748

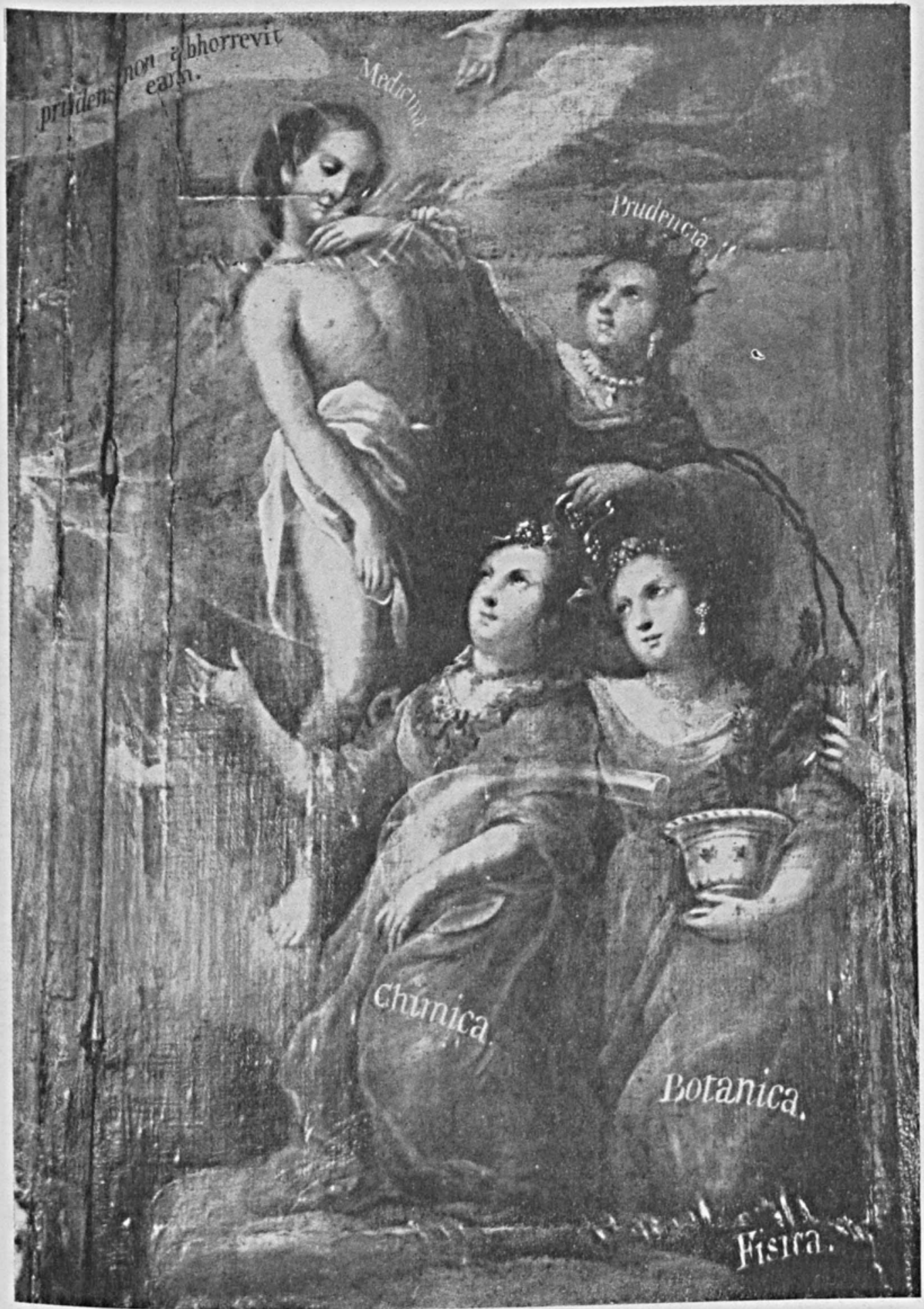

Fig. 7. "La Medicina ... a la que desnudan la Prudencia y la Filosofía... y a sus pies se arrodillan la Quimica y la Botánica... 
DOI: http://dx.doi.org/10.22201/iie.18703062e.1963.32.748

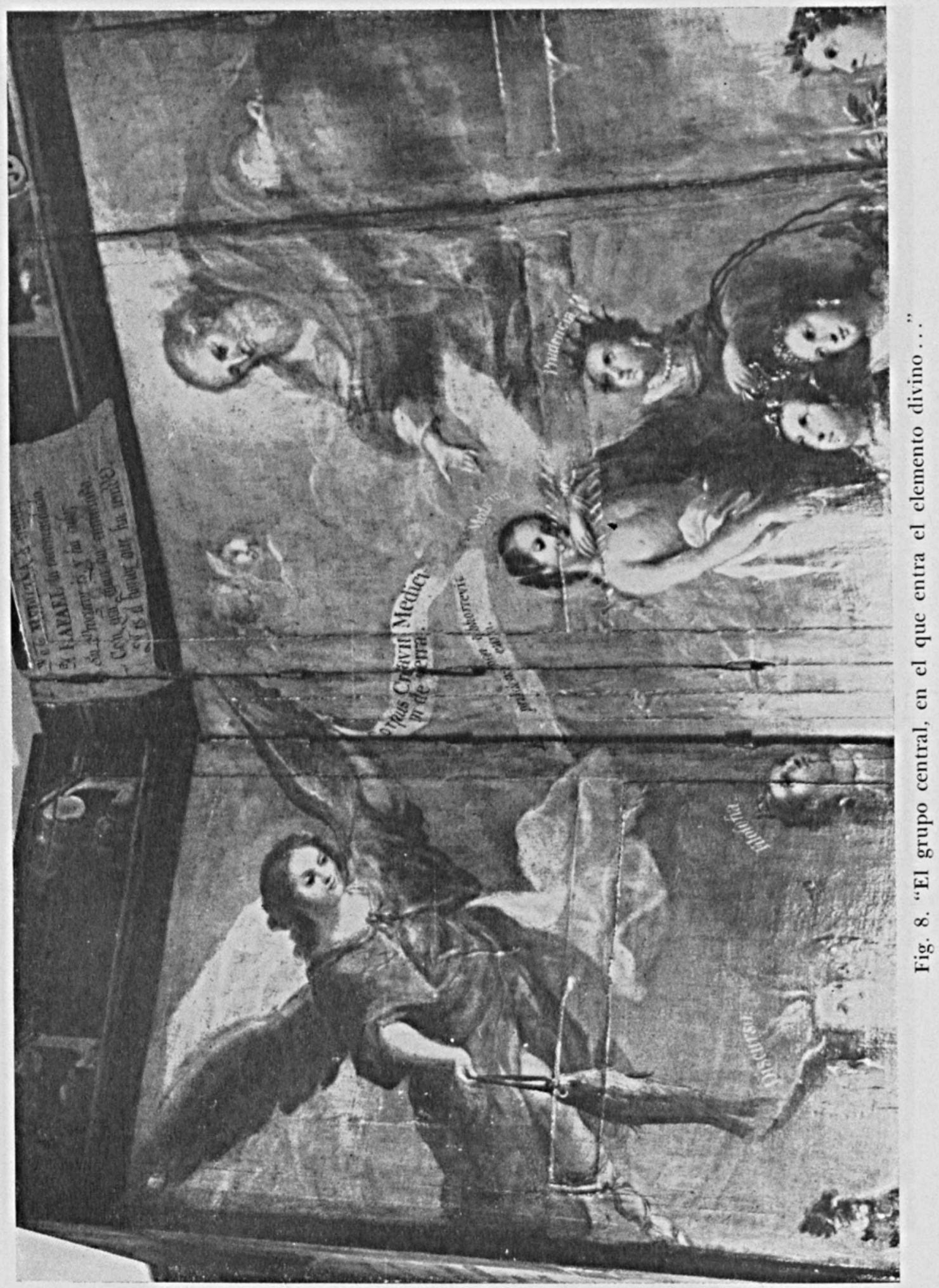


DOI: http://dx.doi.org/10.22201/iie.18703062e.1963.32.748

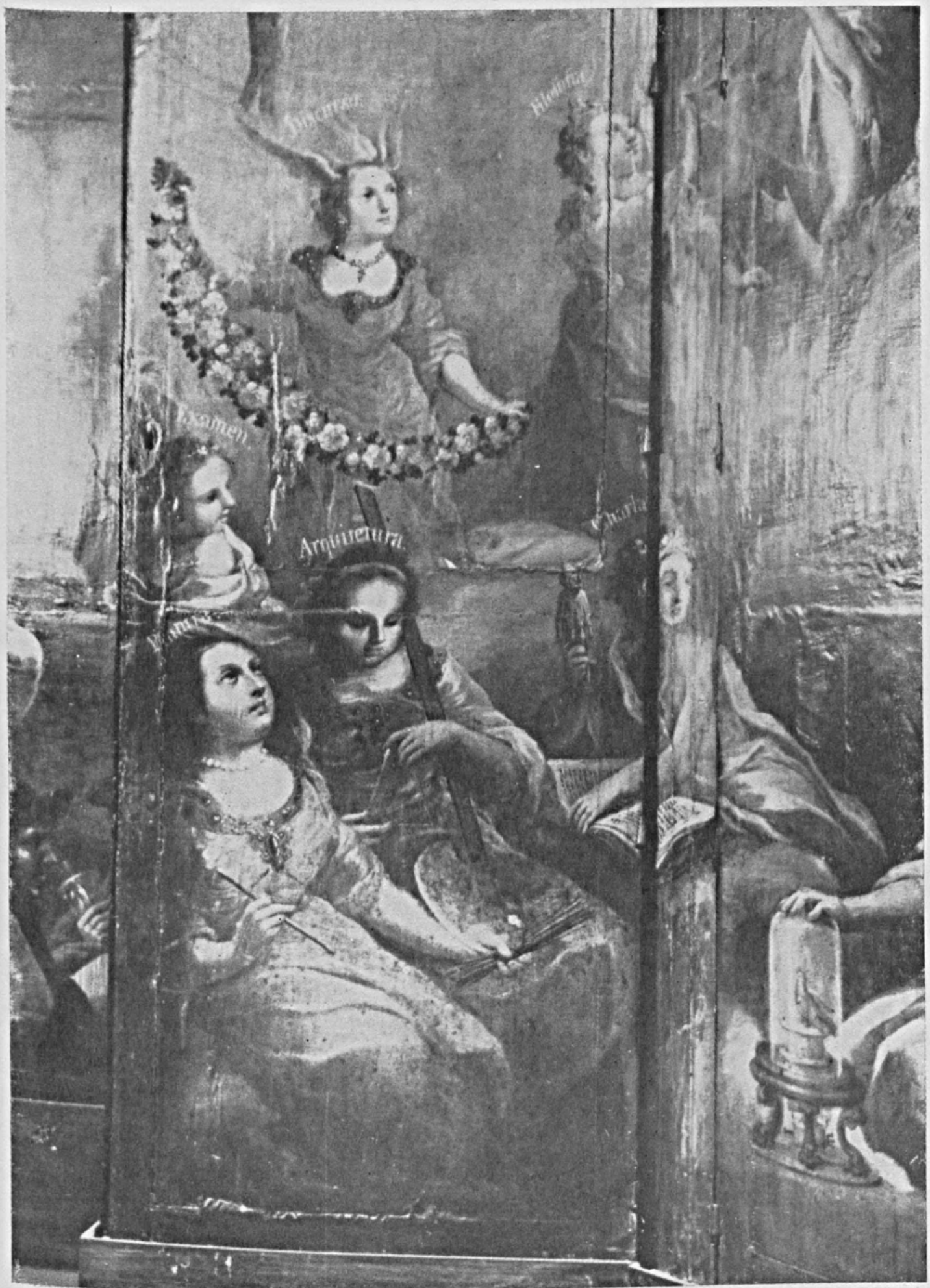

Fig. 9. La Pintura, el Examen, el Discurso, la Arquitectura y la Charlatanería. 
DOI: http://dx.doi.org/10.22201/iie.18703062e.1963.32.748

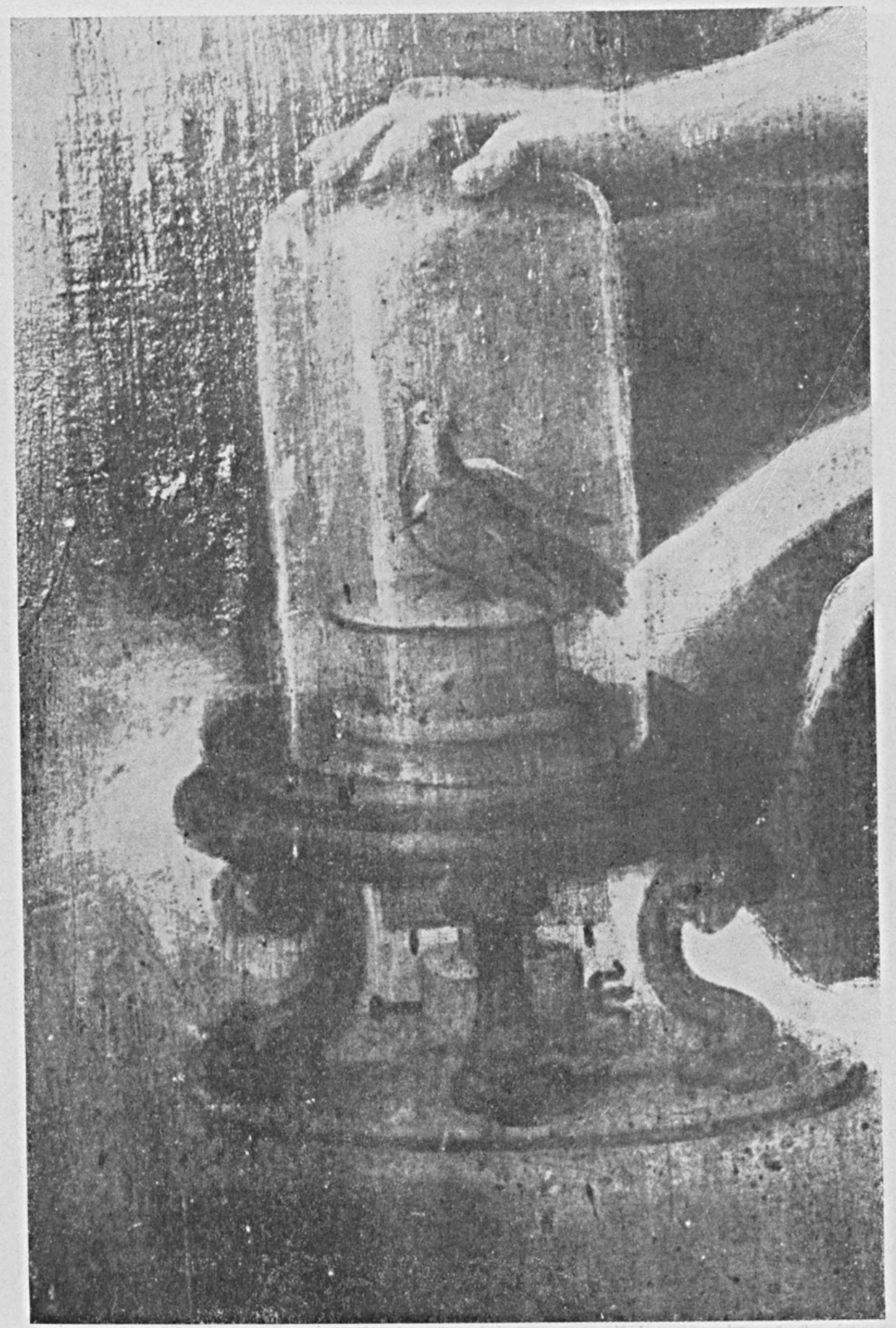

Fig. 10. "... un lindo capelo que encierra un pájaro..." 
DOI: http://dx.doi.org/10.22201/iie.18703062e.1963.32.748

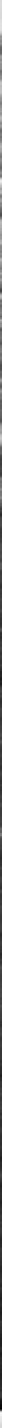

Fig. 11. El Comercio y las Artes Menores.

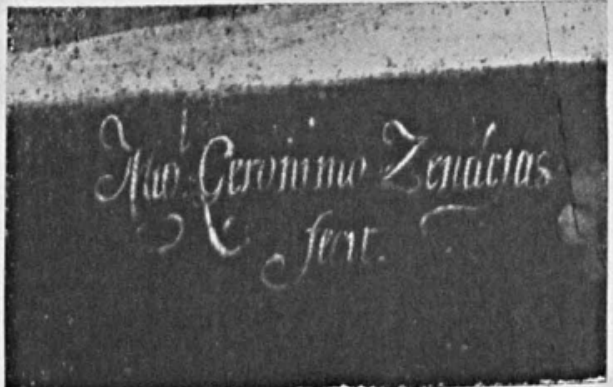

Detalle de la Fig. 4, la firma del pintor. 
DOI: http://dx.doi.org/10.22201/iie.18703062e.1963.32.748

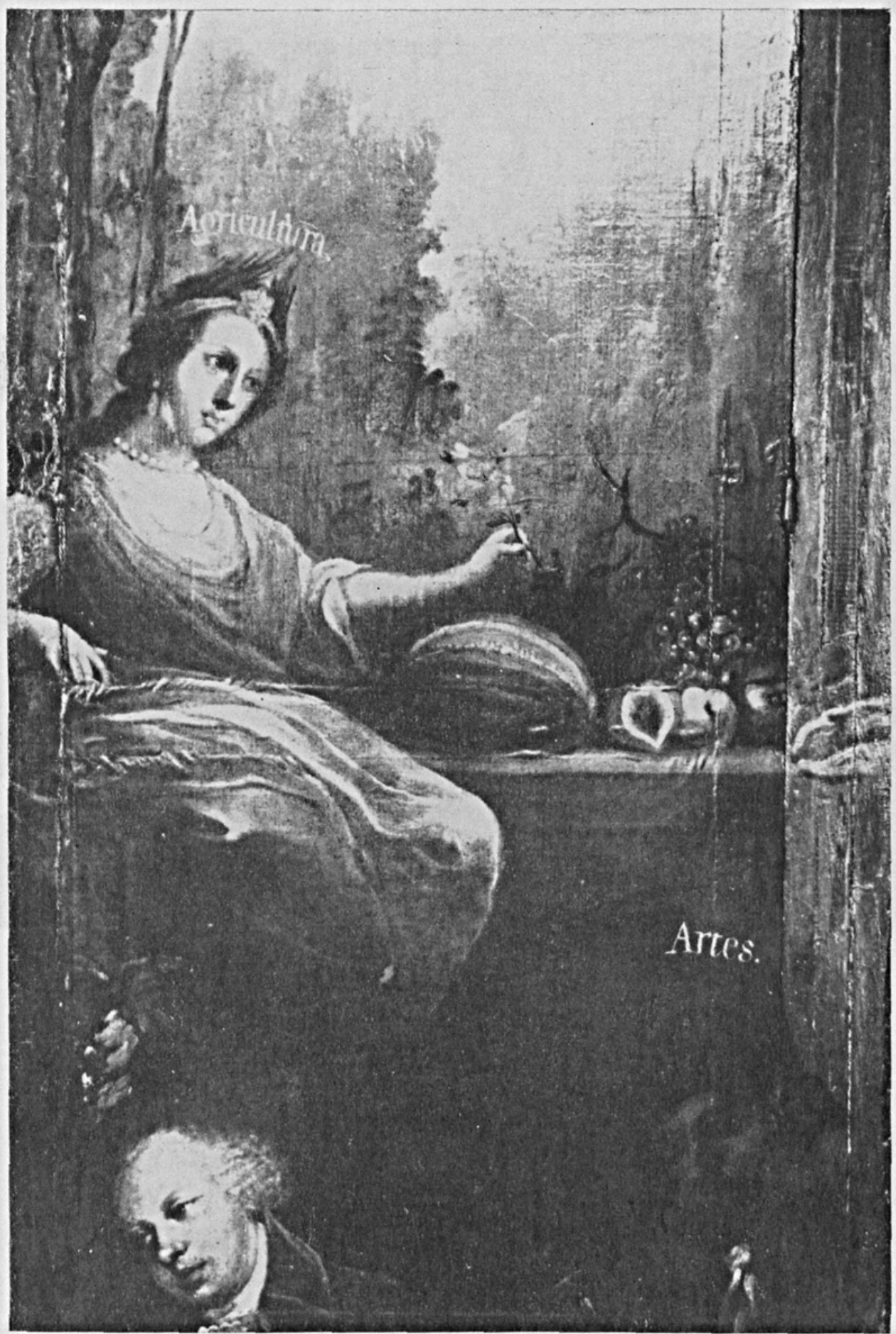

Fig. 12. "La Agricultura, sola, solemne, hermosa y segura ..." 
$Y$ viene después el grupo central, en el que entra el elemento divino, pues en la parte de arriba está el Padre Eterno y a su derecha el arcángel San Rafael llevando en su mano diestra su simbólico pescado y en la izquierda una filacteria con dos letreros: Corpus creavit Medicinam de Terra y E... prudens non abhorrevit eam. (fig. 8)

Sobre ellos esta redondilla con sus faltas de ortografía:

$$
\begin{aligned}
& \text { Ya la MEDICINA a creado, } \\
& \text { a RAFAEL la a encomendado, } \\
& \text { su protector es y ha cido, } \\
& \text { con esta guia ha caminado } \\
& \text { y es el honor que ha tenido. }
\end{aligned}
$$

Las figuras de abajo de la escena religiosa son diez doncellas que representan: La Medicina, ahora como una mujer, una púdica adolescente, aún sin senos, a la que desnudan la Prudencia y la Filosofia, es decir, la ponen al descubierto, sin velos que la oculten, (fig. 7) y a sus pies se arrodillan la Quimica y la Botánica, la primera con una fina retorta de vidrio y la segunda con un tiesto de cerámica pintada con una planta que parece -o lo es, sin dudas- un pequeño y mexicano nopalito.

La Prudencia antes citada lleva unas riendas en su mano izquierda, dándonos a entender su comedimiento y equilibrio y la Filosofía está muy ocupada en desvelar a la Medicina para llevar algo en las manos.

A espaldas de la Botánica anda la Aplicación, muy afanosa en ofrecerle un ramo de laurel a la Medicina y luego el Arte, con una estatuita en las manos y, otra vez, la Naturaleza, con una esfinge. (La primera vez fue la naturaleza decidida que descubre a la salud; ahora es la naturaleza misteriosa, escondiendo sus secretos). Abajo el científico grupo de la Física, que apoya su mano en un lindo capelo que encierra un pájaro; (fig. 10) la Anatomia, con un fino dibujo de un esqueleto y la Astronomia, señalando un punto con un punzón en una poderosa esfera celeste. (fig. 6)

En seguida está colocada una extraña figura: la Charlataneria, una vieja escéptica y agria, coronada de laurel, que hojea un grueso infolio y en su diestra una escultura de un gracioso polichinela. En el letrero que luego pondremos se explica su presencia.

Junto a ella están la Pintura y la Arquitectura; la primera es una matrona de grandes y hermosos ojos, con pinceles y paleta en las manos y la segunda con un triángulo y un nivel. Sobre ellas otras dos figuras 
que son el Examen y el Discurso, ésta última con alas y una lengua de fuego en la cabeza y una guirnalda de flores extendida entre sus manos. (fig. 9) La Discreción y la Experiencia completan el conjunto al que alude el letrero:

La MEDICINA, aquella ilustre ciencia que el ALTísimo al hombre ha preparado, la pudo descubrir sólo el cuidado de APLICACIÓN, FILOSOFIA y PRUDENCIA; de éstas la DISCRECIÓN y la EXPERIENCIA demuestran los dos ejes en que estriba la QUIMICA y BOTÁNICA en que aviva toda su sutileza y su excelencia, por todas partes muestra su decencia, sus proyectos, su alteza, su hermosura; retírese, pues, de ella con violencia la CHARLATANERfA con su locura y vengan libres luego a su presencia el DISCURSO, el examen, la cordura.

Abajo están las Artes, en este caso las que ahora llamamos "Artes Menores", representadas por tres señores jóvenes que llevan en sus manos los objetos de su artesanía o "artes menores" o "artes industriales" (que, no acabando de saber como llamarlas, les aplicamos esos adjetivos). Son el vidrio, la taracea y la platería, representados por una copa, una caja de Uruapan y unos platos y jarras. (fig. 11) El joven que lleva la plata, el más distinguido de los tres y que lleva sombrero de copa, recuerda al gran platero y pintor poblano José Luis Rodríguez Alconedo, hermano del boticario y botánico José Ignacio, ya citado. ¿Será un retrato anterior al maravilloso autorretrato hecho en Cádiz en 1810? Todo lo hace suponer así, con gran verosimilitud. (fig. 11)

El último tablero lleva al Comercio, abajo, representado por un scñor de empolvado peluquín, gordo y complaciente, que trata de convencer que le deje la mercancía más barata (una espléndida tela de brocado) a un tipo de carácter oriental que tal vez recuerda la Nao de la China, paradigma y fiel ejemplo del comercio novohispano. (fig. 11)

Arriba la Agricultura, sola, solemne, hermosa y segura de que sin ella todo lo demás es accesorio; lleva un collar de perlas y se corona de plumas; en una mesa se lucen las frutas: sandía, duraznos, uvas, plátanos . . . (fig. 12) 
Hay, entonces, en resumen:

1. Una invitación a contemplar a las Ciencias.

2. La Medicina, la Salud y la Naturaleza; se ponen de acuerdo.

3. Los científicos junto al Tiempo y la Historia.

4. Las Artes ayudan a la Medicina.

5. La Medicina cerca de Dios.

6. Allí, cerca de Dios, la Prudencia y la Filosofia se atreven a desnuclarla, a darla a conocer con Examen, Discurso, Discreción y Experiencia.

7. Las ciencias auxiliares acompañan a la Medicina, así como el Co. mercio y la Agricultura.

8. La Charlataneria no se olvida y se pone como ejemplo de burla y menosprecio.

El hombre, Sujeto Histórico en el Tiempo, es, en cuanto a su Nituraleza, Saludable, pero, como enfermo, necesita de la Medicina, que Dios le "ha preparado" y a la que sólo pueden "descubrir el cuidado" de la Filosofía, la Prudencia, la Discreción y la Experiencia; sus "dos ejes" son la Botánica, y la Química y como es "sutil, excelente y hermosa", la acompañan las Artes y aun la Agricultura y el Comercio. Nada falta pues, al científico de la "Ilustración", en el camino del Progreso.

No cabe duda que Alconedo, el "ilustrado" boticario, tenía una fértil imaginación. Gracias a él tenemos una pintura que ya no es puramente religiosa y que representa, dignamente, a "La Ilustración" mexicana. 